\title{
ACIL SERVISE BILINÇ DEĞişiKLiĞi iLE BAŞVURAN GERIATRIK HASTALAR
}

\author{
Geriatric Patients With Altered Mental Status Admitted \\ to the Emergency Service
}

Gökhan Elçin ${ }^{1}$, Sadiye Yolcu' ${ }^{2}$ Mücahit Kapç ${ }^{3}$, Vermi Değerli ${ }^{1}$, Burak Gün ${ }^{1}$, İsmet Parlak ${ }^{1}$

\section{ÖZET}

${ }^{1}$ Bozyaka Eğitim ve Araştırma Hastanesi Acil Tıp Kliniği, İmir

${ }^{2}$ Bozok Üniversitesi Tıp Fakültesi, Acil Tıp Anabilim Dall, Yozgat

${ }^{3}$ Adnan Menderes Üniversitesi Tıp Fakültesi, Acil Tıp Anabilim Dalı Aydın

Gökhan Elçin, Uzm. Dr. Sadiye Yolcu, Yrd. Doç. Dr. Mücahit Kapçı, Yrd. Doç. Dr. Vermi Değerli, Uzm. Dr. Burak Gün, Uzm. Dr. İsmet Parlak, Doç. Dr.

\section{İletişim:}

Yrd. Doç. Dr. Sadiye Yolcu Bozok Üniversitesi Tıp Fakültesi Acil Tıp Anabilim Dalı Yozgat Tel: 05053596731

e-mail:

sadiyeyolcu@yahoo.com

Geliş tarihi/Received:20.12.2013 Kabul tarihi/Accepted:14.01.2014
Amaç: Bu çalışmanın amacı bilinç değişikliği ile acil servise başvuran 65 yaş ve üzeri hastaların bilinç bozukluğunun nedenlerine yönelik incelenmesi planlanmaktadır.

Gereç ve Yöntemler: Çalışmamıza acil servisimize 65 yaş ve üstü bilinç değişikliği ile başvuran hastaların dosyaları retrospektif olarak incelendi. Tüm olguların demografik özellikleri, tıbbi durumları, vital bulguları ve ayrıntlı fizik muayene bulguları kaydedildi.

Bulgular: Çalışmaya alınan 104 hastadan 48'i erkek (\%46,2), 56'sı kadındı (\%53,8). Vakaların yaş ortalaması 77,3 idi. Hastaların 98'i $(\% 94,2)$ acil servise yakını ile gelirken 5'i $(\% 4,8)$ bakıcısı ile $1^{\prime} i$ $(\% 0,9) 112$ ambulans personeli ile gelmişti. 67 (\%64.4) hasta hastaneye yatrıldı. En sık konulan tanılar iskemik serebrovasküler hastalık $(\% 16,3)$, pnömoni $(\% 16,3)$ ve sepsis $(\% 15,4)$ idi. Hastalara konulan tanılar ile mortalite ve yatş süresi arasında ilişki kurulamadı.

Sonuç: Sonuç olarak acil servise bilinç bozukluğu ile gelen hastalarda tanıların geniş bir yelpazede olduğu ve şikayeti ani başlayan hastalara dikkat edilmesi gerektiği unutulmamalıdır. Acil tıp hekimleri geriatrik hastalar hakkında daha fazla bilgi beceri kazanmalı ve yaşı hasta bakımı için acil servislerin ihtiyaca yönelik düzenlenmesi gerekmektedir.

Anahtar kelimeler: Bilinç bozukluğu; Acil servis; Geriyatri.

\section{ABSTRACT}

Objective: In this study, patients over age of 65 with altered mental status admitted to the emergency service were specifially investigated.

Materials and Methods: In our study, charts of 104 patients admitted to our emergency service are retrospectively viewed. Demographic characteristics, medical conditions, vital signs, detailed physical examination of the patients were recorded.

Results: Of 104 patients, 48 (46.2\%) were male and 56 (53.8\%) were female. Averaga age was 77.3 $\pm 7.98(94.2 \%)$ of patients were brought to emergency department by relatives while $5(4.8 \%)$ by caregiver and $1(0.9 \%)$ by ambulance personnel. $67(64.4 \%)$ patients were admitted to the hospital. Most common diagnoses were ischemic cerebrovascular disease (16.3\%), pneumonia (16.3\%) and sepsis (\%15.4). There wasn't a correlation between diagnoses with mortality and hospitalization time.

Conclusion: As a result, for geriatric patients admitting consciousness disorders have a wide range of diagnoses, concern must be given to patients with sudden onset complaints. Emergency physicians need to learn more practice about geriatric patients and emergency services for the care of elderly patients have to be tailored to the needs.

Key words: Consciousness Disorders; Emergency service; Geriatrics. 


\section{Giriş}

Yaşlanma, canlı organizmaların, türe özel bir zaman süresinde, iç ve dış çevredeki değişikliklere uyum yeteneğinin azalması sonucu, homeostazisi sürdüremedikleri, birden fazla patolojinin ve onlara ait belirti ve bulguların sıklıkla birlikte bulunduğu yaşam dönemidir (1).

Yaşlı ve bilinç değişikliği ile gelen hasta sayısı da her geçen gün artmaktadır. Bu hastalar acil servislerde daha fazla zaman geçirmekte, klinik prezentasyonlarıda atipik olduğundan daha fazla tetkik edilmektedirler $(2,3)$. Literatürü incelediğimizde genel olarak 65 yaş üzeri hastaların acil servis başvurularının incelendiğini spesifik olarak bilinç bozukluğunun nedenlerine yönelik incelenmediğini gördük. Çalışmamızın özellikle bu bilimsel veri eksikliğini gidereceğini düşünmekteyiz.

\section{GEREÇ VE YÖNTEM}

Çalışmamıza 1 Ağustos 2011 - 30 Eylül 2011 tarihleri arasında Bozyaka Eğitim ve Araştırma Hastanesi Acil Servisine başvuran 65 yaş üstü bilinç bozukluğu şikayeti ile gelen hastalar alındı. Tüm olguların yaş, cinsiyet, acile başvuru şikayetleri, anamnezi veren kişi, şikayetin başlama zamanı, hastanın mobil olma durumu, komorbid hastalıkları, kullandığı ilaçlar ve ilaçlarını düzenli alıp almadığı, vital bulguları, ayrıntılı fizik muayene bulguları kaydedildi. Tetkik sonrası hastaların aldığı tanı, istenen konsültasyonlar, hastanın nasıl sonuçlandığı kaydedildi. Ayrıca araştırma ile ilgili Bozyaka Eğitim ve Araştırma Hastanesi Eğitim Planlama Kurulu'ndan onay alındı.

Çalışmada elde edilen bulgular değerlendirilirken, istatistiksel analizler için SPSS (Statistical Package for Social Sciences) for Windows 15.0 programı kullanıldı. Çalışma verileri değerlendirilirken tanımlayıcı istatistiksel metodların (Ortalama, Standart sapma) yanı sıra niceliksel verilerin karşılaştırılmasında normal dağılım gösteren parametrelerin gruplar arası karşılaştırmalarında student t testi kullanıldı; normal dağılım göstermeyen parametrelerin gruplar arası karşılaştırmalarında ise Mann Whitney U test kullanıldı. Niteliksel verilerin karşılaştırılmasında ise Ki-Kare testi ve Fisher Exact Ki-Kare testi kullanıldı. Sonuçlar \% 95'lik güven aralığında, anlamlılık $\mathrm{p}<0,05$ düzeyinde değerlendirildi.

\section{BULGULAR}

Çalışmaya 104 hasta alındı. Hastaların 48'i erkek $(\% 46,2)$, 56'sı kadındı (\%53,8). Vakaların yaş ortalaması 77,3 \pm 7 idi. Minimum yaş 65 maksimum yaş 96 idi. Hastaların 64'ü $(\% 61,5)$ ambulans ile, 40’ı $(\% 38,5)$ kendi imkanları ile acil servise başvurdu.

Tablo 1. Acil servise bilinç değişikliği ile başvuran hastalarda eşlik eden şikâyetlerin ve şikayetin başlama zamanı dağııımı

\begin{tabular}{|c|c|c|}
\hline & $\mathbf{n}$ & $\%$ \\
\hline \multicolumn{3}{|l|}{ Acile Geliş Şikayeti } \\
\hline Nefes Almada Zorluk & 19 & 18,3 \\
\hline Ateş & 18 & 17,3 \\
\hline Yemek yememe & 15 & 14,4 \\
\hline Bulant-kusma & 9 & 8,6 \\
\hline İshal & 5 & 4,8 \\
\hline Kasılma & 4 & 3,8 \\
\hline Göğüs ağrısı & 4 & 3,8 \\
\hline Vücut yarısında güçsüzlük & 4 & 3,8 \\
\hline Öksürük & 3 & 2,9 \\
\hline Morarma & 3 & 2,9 \\
\hline İdrar kaçırma & 1 & 0,9 \\
\hline Boğaz ağrısı & 1 & 0,9 \\
\hline Baş ağrısı & 1 & 0,9 \\
\hline Karın ağrısı ve şişlik & 1 & 0,9 \\
\hline Bel ağrısı & 1 & 0,9 \\
\hline Şeker yüksekliği & 1 & 0,9 \\
\hline Yan ağrısı & 1 & 0,9 \\
\hline Ek şikayet yok & 13 & 12,5 \\
\hline Toplam & 104 & 100 \\
\hline \multicolumn{3}{|l|}{ Şikayetin başlama zamanı } \\
\hline Aniden & 54 & 51,9 \\
\hline 0-6 saat önce & 6 & 5,8 \\
\hline 6-12 saat önce & 3 & 2,9 \\
\hline 12-24 saat önce & 3 & 2,9 \\
\hline$>24$ saat önce & 38 & 36,5 \\
\hline Toplam & 104 & 100 \\
\hline \multicolumn{3}{|l|}{ Hastanın sonlanma durumu } \\
\hline Servise yatiş ve taburcu & 41 & 39,42 \\
\hline Taburcu & 19 & 18,27 \\
\hline Sevk & 12 & 11,54 \\
\hline Serviste eksitus & 12 & 11,54 \\
\hline Yoğun bakımda eksitus & 10 & 9,62 \\
\hline Acilde eksitus & 6 & 5,77 \\
\hline Yoğun bakım yatış ve taburcu & 4 & 3,85 \\
\hline Toplam & 104 & 100 \\
\hline
\end{tabular}


Hastaların $98^{\prime} i(\% 94)$ acil servise yakını ile gelirken, $5^{\prime} i$ $(\% 4,8)$ bakıcısı ile 1'i $(\% 1) 112$ ambulans personeli ile gelmişti. Bu hastaların 39'u (\%37,5) mobil, 27'si (\%26) immobil, 38' i $(\% 36,5)$ kısmi mobildi. Hastaların 42'si $(\% 40,4)$ ilaçlarını düzenli kullanırken, 62'si $(\% 59,6)$ düzensiz ya da hiç ilaç kullanmıyordu. Hastaların 44 'ünün $(\% 42,3)$ dil kuruluğu minimal iken, 34'ünde (\% 32,7) orta derece dil kuruluğu, $26^{\prime}$ sında $(\% 25,0)$ ileri derece dil kuruluğu mevcut idi .Cinsiyet ile acil servise başvuru şikâyeti arasında anlamlı ilişki kurulamadı $(p>0,05)$. Aynı şekilde cinsiyet ile; beraberinde acile geldiği kişi, acile başvuru süresi, ilaçlarını düzenli kullanıp kullanmama $(p>0,05)$, vital bulgular $(p>0,05)$, acil serviste geçirilen süre $(p>0,05)$, acil servisteki sonlanım şekli $(p>0,05)$ arasında anlamlı ilişki kurulamadı. Bilinç değişikliği ile acil servise gelen hastalarda eşlik eden şikâyetleri, şikâyetlerin başlama zaman dilimi ve hastaların sonuçlanma şekillerinin dağılımı tablo 1 'de gösterilmiştir. Hastaların 16' sının $(\% 15,4)$ bilinen kronik hastalığı yoktu. 88 hastanın $(\% 84,6)$ en az bir kronik hastalı̆ı vardı. Hastalarımızın cinsiyet ile bilinen kronik hastalıklarından kalp yetmezliği ve KOAH arasında anlamlı ilişki ku- ruldu $(p<0,05)$. Buna göre kalp yetmezliği en çok kadınlarda gözlenirken $\mathrm{KOAH}$ en çok erkeklerde gözleniyordu $(p<0,05)$. Hastaların acil serviste aldıkları tanıların dağılımı tablo 2'de verilmiştir. Hastaların $29(\% 27,9)$ tanesi dahiliye servisine yatrıldı. Hastalardan istenen konsültasyonların bölümlere göre dağııımı ve yatrıldıkları servisler Tablo 3'te verilmiştir.

Yaş ile; acil servise geliş süresi ( $p>0,05)$, vital bulgular $(p>0,05)$, sonlanım şekli $(p>0,05)$ ve hastane içi mortalite $(p>0,05)$ arasında anlamlı ilişki saptanamadı. Hastaları 65-80 ve 81 üstü olarak gruplandırdığımızda ise kronik hastalıkların ilk grupta daha fazla görüldüğünü $\operatorname{saptadık}(p<0,05)$. Şikâyeti aniden başlayan grubun acilde en fazla süre kalan grup olduğu saptandı. İstatistiksel olarak ispatlandı $(p<0,05)$. Şikâyeti aniden başlayan grubun daha fazla hastanede kaldığı görüldü, istatistiksel olarak ispatlandı $(p<0,05)$. Ancak şikâyeti aniden başlayan grup ile hastaların sonlanım şekli arasında anlamlı ilişki kurulamadı $(p>0,05)$. Hastane içi mortalite ile; cinsiyet, yaş, başvuru şikayeti, şikayetin başlama zamanı arasındaki ilişki araştıııdı, anlamlı ilişki kurulamadı $(p>0,05)$ (Tablo 4).

Tablo 2. Tanıların Dağılımı

\begin{tabular}{|c|c|c|c|}
\hline Tanı & n (\%) & Tanı & n (\%) \\
\hline Serebrovasküler & $25(24)$ & Nefrolojik Hastalıklar & $13(\% 12,5)$ \\
\hline hastalıklar & & Akut Böbrek Yetmezliği & $3(2,9)$ \\
\hline İskemik SVO & $17(16,3)$ & Kronik Böbrek Yetmezliği & $3(2,9)$ \\
\hline Hemorajik SVO & $5(4,8)$ & Elektrolit Bozukluğ & $7(6,7)$ \\
\hline Multiple Skleroz atak & $1(0,9)$ & Endokrinolojik Hastalıklar & $8(7,7)$ \\
\hline Epilepsi & $2(1,9)$ & Hiperosmolarnonketotik & $1(0,9)$ \\
\hline Pulmoner Hastalıklar & $24(23)$ & koma & \\
\hline Pnömoni & $17(16,3)$ & Diabetik Ketoasidoz & $2(1,9)$ \\
\hline Koah alevlenme & $3(2,9)$ & Hipoglisemi & $5(4,8)$ \\
\hline Pulmoner Emboli & $2(1,9)$ & Enfeksiyon Hastalıkları & $15(14,4)$ \\
\hline $\begin{array}{l}\text { Solunum yetmezliği } \\
\text { (tanı konamamış) }\end{array}$ & $2(1,9)$ & Sepsis & $15(14,4)$ \\
\hline Kardiyovasküler & $14(13,5)$ & Onkolojik Hastalıklar & $3(2,9)$ \\
\hline Hastalıklar & & Malignite & $3(2,9)$ \\
\hline Akut Koroner Sendrom & $4(3,8)$ & Gastrointestinal & $1(0,9)$ \\
\hline Aritmi & $5(4,8)$ & Hastalıklar & \\
\hline Kardiyak Senkop & $2(1,9)$ & Hepatik Ensefalopati & $1(0,9)$ \\
\hline Hipotansif Atak & $1(0,9)$ & Cerrahi Hastalıklar & $1(0,9)$ \\
\hline Pulmoner Ödem & $2(1,9)$ & Mezenter İskemisi & $1(0,9)$ \\
\hline
\end{tabular}


Tablo 3. İstenen Konsültasyonların Dağııımı

\begin{tabular}{lllll}
\hline & \multicolumn{2}{l}{ İstenen konsültasyonlar } & \multicolumn{2}{l}{ Yatş̧ yapılan bölüm } \\
\hline & $\mathrm{n}$ & $\%$ & $\mathrm{n}$ & $\%$ \\
Dahiliye & 52 & 50 & 29 & 27,9 \\
Nöroloji & 35 & 33,6 & 16 & 15,4 \\
Beyin cerrahi & 7 & 6,7 & 5 & 4,8 \\
Göğüs hastalıkları & 9 & 8,6 & 2 & 1,9 \\
Kardiyoloji & 7 & 6,7 & 3 & 2,9 \\
Enfeksiyon hastalıkları & 16 & 15,4 & 6 & 5,8 \\
Nefroloji & 6 & 5,8 & 0 & 0 \\
Anestezi ve yoğun bakım & 10 & 9,6 & 6 & 5,8 \\
Genel cerrahi & 4 & 3,8 & 0 & 0 \\
Ortopedi & 1 & 0,9 & 0 & 0 \\
Üroloji & 1 & 0,9 & 0 & 0 \\
Kalp damar cerrahisi & 1 & 0,9 & 0 & 0 \\
\hline
\end{tabular}

Tablo 4. Şikayetlerin Başlama Zamanı ile Hastane İçi Mortalite Illişkisi

\begin{tabular}{lllll}
\hline & $\begin{array}{l}\text { Acilde eks. } \\
\mathrm{n}(\%)\end{array}$ & $\begin{array}{l}\text { Serviste eks } \\
\mathrm{n}(\%)\end{array}$ & $\begin{array}{l}\text { Yoğun Bakımda eks } \\
\mathrm{n}(\%)\end{array}$ & $\begin{array}{l}\text { Toplam } \\
\mathrm{n}(\%)\end{array}$ \\
\hline $\begin{array}{l}\text { Şikayet başlama } \\
\text { Zamanı }\end{array}$ & & & & \\
Aniden & $2(7,14)$ & $4(14,28)$ & $5(17,85)$ & $\mathbf{1 1 ( 3 9 , 3 )}$ \\
0-6 saat & $1(3,57)$ & 0 & $2(7,14)$ & $\mathbf{3 ( 1 0 , 7 )}$ \\
6-12 saat & 0 & $1(3,57)$ & 0 & $\mathbf{1 ( 3 , 8 )}$ \\
$\begin{array}{l}\text { 12-24 saat } \\
\text { 24 saat üstü }\end{array}$ & 0 & 0 & 0 & $\mathbf{0}$ \\
$\begin{array}{l}\text { Toplam } \\
\mathrm{n} \text { (\%) }\end{array}$ & $\mathbf{3 ( 1 0 , 7 1 )}$ & $\mathbf{7 ( 2 5 , 0 )}$ & $3(10,71)$ & $\mathbf{1 3 ( 4 6 , 4 )}$ \\
\hline
\end{tabular}

\section{TARTIŞMA}

Toplumdaki yaşlı oranının günden güne artmasına bağlı olarak acil servislere başvuran geriatrik hasta populasyonu da artş̧ göstermektedir. Türkiye İstatistik Kurumunun 2010 tarihli verilerine göre yurdumuzdaki 65 yaş üstü nüfus oranı \% 7,2'dir, İzmir'de yaşayan yaşı nüfus oranı ise \% 8,3'dür (4).Çalışmaya aldığımız hastaların 56 'sı $(\% 53,8)$ kadın, 48'i (\% 46 ) erkekti. Şahin ve arkadaşlarının 2011 tarihli yaptı̆ı çalışmada oran 7709 (\% 50,3) kadın, $7630(\%$ 49,7) erkek olarak tespit edilmiş (2). Karadağ ve arkadaşlarının yaptığı çalışmada ise kadınların oranı $\% 54,2$, erkeklerin oranı ise $\% 45,8$ olarak saptanmış. Bu oranlar bizim verilerimize yakın değerlerdi (3). Literatürü incelediğimizde; 65 yaş üzeri acil servise olan başvurular incelendiğinde, Ünsal ve arkadaşlarının yaptı̆ı̆ı çalışmada en sık kardiyovasküler $(\% 19,6)$ ve pulmoner $(\% 17,8)$ nedenler saptanmış $(5)$. Ross ve arkadaşları acil servise başvuruda en çok şikâyetin \% 24 oranı ile göğüs ağrısı olduğunu saptamış (6). Farkı olarak Hu ve arkadaşlarının yaptı̆̆ı çalışmada sonuçlarımızla uyumlu olarak serebrovasküler sistem kaynaklı şikâyetler ön planda saptanmış (7). 
Bizim çalışmamızda bilinç değişikliği ile acil servis başvurusu yapan 65 yaş ve üstü hastalarda ateş, nefes almada zorluk, yemek yememe, bulant-kusma gibi ek şikâyetlerin ön plana çıktğ̆ı görülmektedir. Bilinç değişikliği olan geriatrik hastaların şikâyetlerinin çok geniş yelpazede olduğu çalışmamızda dikkat çekiciydi.

Literatüre baktı̆ı̆ımıda diğer çalışmalarda genel olarak 65 yaş ve üzeri hastaların acil servise başvuru şikayetlerinin incelendiğini ve spesifik olarak bilinç bozukluğunun nedenlerine yönelik incelenmediğini görüyoruz.

Çalışmamızda başvuru şikâyetlerinin cinsiyetlere göre dağııımı ve ilişkisini de araştırdık, istatistiksel olarak anlamlı bulamadık. E. Mert'in 65 yaş üstü hastaları incelediği çalışmada malignite nedeni ile başvuruları daha çok erkeklerde, kaza-travma nedeni ile başvuruları da daha çok kadınlarda saptamış. Diğer nedenler arasında fark bulunamamış (8).

Ünsal ve arkadaşlarının yapttğı çalışmada kadınlarda hipertansiyon ve üst solunum yolu enfeksiyonu nedeni ile başvurunun daha sık; erkeklerde ise pulmoner kökenli hastalığın daha sık başvuru nedeni olduğu saptanmış (5). Castella ve arkadaşlarının yaptığı çalışmada ise cinsiyetler arasında başvuru şikâyeti açısından anlamlı fark bulunamamış (90). Çalışmamızda hastalarımızın 88 (\% 84 )'inde en az bir bilinen kronik hastalık vardı. Erkeklerde $\% 87,5$ oranında kadınlarda $\% 82,1$ oranında kronik hastalık saptandı. Ancak istatistiksel olarak anlamlı ilişki kurulamadı. Hastalarımızda kronik hastalık olarak en fazla oranda hipertansiyon $43(\% 41,3)$ hastada ve diyabetes mellitus $31(\% 29,8)$ hastada görüldü.

Bilinç bozukluğu ile başvuran geriatrik hastaların acil servis başvuruları, acil servisten hastaneye yatrııma oranlarının da yüksekliği dikkat çekicidir. Geriatrik hastaların yaşlanma ile oluşan fizyolojik değişikliklerinin yanında, eşlik eden kronik hastalıklarının olması, çoklu ilaç kullanımlarının olması mevcut durumlarının değerlendirmesini zorlaştırmaktadır. Bilinç bozukluğu ile başvuran geriatrik hastaların değerlendirilmesinde multidisipliner bir yaklaşımın gerekliliği aşikârdır (10). Çalışmamızda acil servisten istenen konsültasyonlar arasında en sık dahiliye kliniği (\%50), 2. en sık nöroloji kliniği $(\% 33,6)$ 'nden konsültasyon istenmiş olarak tespit edildi. Taymaz T.'nin çalışmasında ise en çok kardiyoloji (\%22), nöroloji (\%16), dâhiliye (\%11) konsültasyonlarının istendiği saptanmış (11). Hastanemizde nöbet şartlarında kardiyoloji, göğüs hastalıkları, nefroloji klinikleri olmadığından bu klinikler için istenen konsültasyonlar da dâhiliye kliniğinden istenmektedir. Dolayısı ile sonuçlarımız benzerdi. Geriatrik hasta grubunun başvuru sayısının yüksek olduğu acil servislerde özellikle bilinç değişikliği ile başvuran yaşlı hastaların acil servislerde sonuçlandırııması için geçen sürenin kısalmasında, hastanede bulunan birçok kliniğin katkısı gerekmektedir.

Demografik verilerden de görüldüğü gibi acil servislere her geçen gün bilinç değişikliği ile gelen yaşlı hasta başvurusu artmaktadır. Yaşlı hastalar acil servislerde daha fazla zaman geçirmekte ve klinik prezentasyonları da daha önce belirttiğimiz gibi atipik olduğundan daha fazla tetkik gerekmektedir. Bilinç değişikliği ile acil servise başvuran yaşlı hastalardan şikâyetleri aniden başlayanlar ile 24 saat ve üzerinde olanlara daha çok dikkat etmeli, şikâyetlerin çok geniş yelpazede olabileceğini akıldan çıkarmamalıyız. Ateş, nefes almada zorluk, yemek yememe şikâyetleri olanlara özellikle dikkat etmeliyiz. Vital bulguların da çok farklı olduğu ancak ateş yüksekliği, TA düşüklüğü, nabız sayısının yüksekliğinin özellik arzettiğini unutmamalıyız.

Bilinç değişikliği ile acil servise başvuran geriatrik hastalar elektrolit bozukluğu açısından mutlaka değerlendirilmeli, bilinç değişikliği yapan durumlardan birisi olarak elektrolit bozuklukları akıldan çıkarılmamalıdır. Yaşlanma ile birlikte beslenme alışkanlıklarının da değişebileceği, susama hissinin azalmasına bağlı su içmenin azalacağı akılda tutulmalı, bilinç değişikliği ile gelen yaşIı hastalarda mutlaka dil kuruluğuna da bakılmalıdır.

Han ve arkadaşları yaşlı ve bilinç bozukluğu olan hastalarda enfeksiyonların deliryumu en çok presipite eden faktör olduğunu fakat mental durumunda akut değişiklik olan hastalarda bir çok eşlik eden faktör olabileceğini ve bu hastalarda acil değerlendirmenin altta yatan nedene odaklanarak yapılması gerektiğini bildirmişler$\operatorname{dir}(12)$. 


\section{SONUÇ}

Acil servis hekimleri geriatrik hastalar hakkında daha fazla bilgi ve beceri kazanmalı, yaşlı hasta bakımı için acil servisler ihtiyaca yönelik olarak düzenlenmelidir. Gerektiğinde hızlı davranmak hayat kurtarıcı olacaktır. Bu konuda acil servis hekimlerine büyük iş düşmektedir.

\section{KAYNAKLAR}

1. Akan $P$, Erdinçler D, Tezcan V. Yaşlıda Illaç Kullanımı. Turkish J Geriatr. 1999;2(1):33-8.

2. Şahin $S$, Boydak B, Savaş $S$. Acil servise başvuran 65 yaş üzeri hastaların özellikleri. Acad Geriatr. 2011;3(1):41-6.

3. Karadağ $B$, Çat $H$, Öztürk AO. Acil servise başvuran hasta profili 3 yıllık inceleme. Acad Geriatr. 2010 ;2(3):176-85. 4. Adrese Dayalı Nüfus Kayıt Sistemi (ADNKS) Sonuçları. http://tuikapp.tuik.gov.tr/adnksdagitapp/adnks.zul. 5. Ünsal A, Çevik A, Metintaş M. Yaşlı hastaların acil servis başvuruları. Turkish J Geriatr. 2003; 6(3):83-8.

6. Ross MA,Compton S, Richarson D. The use of an emergency department observation unit for elderly patients. Ann Emerg Med. 2003; 41(5): 668-77.

7. Hu SC, Yen D, Yu YC. Elderly use of the ED in an Asian metropolis. Am J Emerg Med. 1999 ;17(1):95-9.

8. Mert E. Geriatrik hastaların acil servis kullanımı. Turkish Journal of Geriatrics. 2006;9(2):70-4.

9. Castella X, Mompart A, Perez G. Hospital utilization for acute problems of elderly. Catalonia, 1982-1990. Gac sanit. 1997;11(6):259-65.

10. Chen JC. Differences of disease Characteritics between genders in emergency department elderly of a community hospital in Taiwan. Changgeng Yi Xue Za Zhi. 2000;23(4):190-6.

11. Taymaz T. Acil polikliniğinden yatırılan geriatrik hastaların ayrıntilı irdelenmesi. Akademik Geriatri. 2010;2(3):167-75.

12. Han JH, Wilber ST. Altered mental status in older patients in the emergency department. Clin Geriatr Med. 2013;29(1):101-36 